\title{
High cardiovascular mortality in Russia: role of alcohol versus smoking, blood pressure, and treatment
}

David A. Leon and Majid Ezzati

We thank Dr Sergei Jargin for his Correspondence (Cardiovascular mortality trends in Russia: possible mechanisms. Nat. Rev. Cardiol. doi:10.1038/nrcardio.2015.166) ${ }^{1}$ on our Review (Ezzati, M. et al. Contributions of risk factors and medical care to cardiovascular mortality trends. Nat. Rev. Cardiol. 12, 508-530; 2015). ${ }^{2}$ We agree with Jargin's concluding paragraph that a number of reasons explain why cardiovascular disease (CVD) mortality is, and has been, so high in Russia compared with most other industrialized countries. The quality of health care (primary and secondary prevention) in Russia-with low levels of treatment with, and compliance to, antihypertensive medications-is almost certainly an important contributor to the high CVD mortality. ${ }^{3}$ To this factor, we would add the high prevalence of current smoking among men, which has been fairly constant at $\geq 60 \%$ since the early 1990s. ${ }^{4,5}$ Regarding alcohol, a great deal of evidence now indicates that a pattern of drinking ethanol-based spirits to intoxication - a fairly common feature of drinking in Russia-is associated with an increased risk of cardiovascular events and death. ${ }^{5,6}$ There are also likely to be contributions from dietary factors, although these have proved difficult to identify, with the proatherogenic lipid profile generally associated with increased CVD mortality not being found in Russia. ${ }^{7}$

Although the average difference in CVD mortality in Russia compared with other countries involves all these important factors, alcohol is distinctive in that it remains the strongest explanation of the very sharp and unprecedented fluctuations in cardiovascular and all-cause mortality seen in Russia since the mid-1980s. ${ }^{8-11}$ Jargin is in partial agreement with us on this matter, describing the sudden decline in mortality seen in the mid-1980s as being a consequence of President Gorbachev's antialcohol campaign, and that alcohol was also implicated in the very steep increase in CVD and all-cause mortality that followed the collapse of the Soviet Union in the first half of the 1990s. We have undertaken detailed analyses of the cause-specific profile of these fluctuations, and have shown that the causes most likely to respond to sharp changes in the prevalence of heavy drinking (injuries and violence, cirrhosis, as well as explicitly alcohol-related causes such as acute alcohol poisoning) are the ones that fluctuated the most. ${ }^{8,11,12}$ Moreover, this cause-specific 'fingerprint' is also seen in the acute changes in mortality that occurred in 1998 and thereafter. The declines in cardiovascular mortality that have been seen since the mid-2000s, however, have some novel features, such as appreciable reductions in cerebrovascular disease mortality among women aged $>65$ years, that might indicate improvements in treatment of hypertension. ${ }^{8}$

As our Review ${ }^{2}$ makes clear, a number of puzzling features of CVD mortality trends in Russia and in other countries remain. Issues of misclassification of cause of death are important. We believe that these misclassifications are primarily within the overall category of CVD, rather than being, for example, misdiagnosed acute alcohol poisonings. We concur with Jargin that some of these might be owing to the quality of autopsy diagnoses in Russia. These and other issues are currently being investigated in a series of studies that will hopefully clarify some of the reasons for Russia's very high burden of CVD.
Department of Non-Communicable Disease Epidemiology, Faculty of Epidemiology and Population Sciences, London School of Hygiene \& Tropical Medicine, Keppel Street, London WC1E 7HT, UK (D.A.L.).

MRC-PHE Centre for Environment and Health, School of Public Health, Imperial College London, Norfolk Place, London W2 1PG, UK (M.E.). Correspondence to: D.A.L. david.leon@lshtm.ac.uk

Competing interests

The authors declare no competing interests.

1. Jargin, S. V. Cardiovascular mortality trends in Russia: possible mechanisms. Nat. Rev. Cardiol. http://dx.doi.org/10.1038/ nrcardio.2015.166.

2. Ezzati, M. et al. Contributions of risk factors and medical care to cardiovascular mortality trends. Nat. Rev. Cardiol. 12, 508-530 (2015).

3. Roberts, B., Stickley, A., Balabanova, D., Haerpfer, C. \& McKee, M. The persistence of irregular treatment of hypertension in the former Soviet Union. J. Epidemiol. Community Health 66, 1079-1082 (2012).

4. Perlman, F., Bobak, M., Gilmore, A. \& McKee, M. Trends in the prevalence of smoking in Russia during the transition to a market economy. Tob. Control 16, 299-305 (2007).

5. Giovino, G. A. et al. Tobacco use in 3 billion individuals from 16 countries: an analysis of nationally representative cross-sectional household surveys. Lancet $\mathbf{3 8 0}$, 668-779 (2012).

6. Roerecke, M. \& Rehm, J. Irregular heavy drinking occasions and risk of ischemic heart disease: a systematic review and metaanalysis. Am. J. Epidemiol. 171, 633-644 (2010).

7. Leon, D. A. et al. Hazardous alcoho consumption is associated with increased levels of B-type natriuretic peptide: evidence from two population-based studies. Eur. J. Epidemiol. 28, 393-404 (2013).

8. Shkolnikov, V. M., Andreev, E., McKee, M. \& Leon, D. A. Components and possible determinants of decrease in Russian mortality in 2004-2010. Demographic Research 28, 917-950 (2013).

9. Leon, D. A., Shkolnikov, V. M. \& Mckee, M. Alcohol and Russian mortality: a continuing crisis. Addiction 104, 1630-1636 (2009).

10. Shkolnikov, V. M. et al. Mortality reversal in Russia: the story so far. Hygiea Internationalis 4, 29-80 (2004).

11. Leon, D. A. et al. Huge variation in Russian mortality rates 1984-94: artefact, alcohol, or what? Lancet 350, 383-388 (1997).

12. Shkolnikov, V., McKee, M. \& Leon, D. A. Changes in life expectancy in Russia in the mid-1990s. Lancet 357, 917-921 (2001). 